\title{
Carbon dioxide - Way forward for the Refrigeration, Air Conditioning and Heat Pump Industry
}

\author{
Leelananda Rajapaksha
}

\begin{abstract}
Carbon dioxide $\left(\mathrm{CO}_{2}\right)$ is a non-toxic, non-flammable natural refrigerant that does not contribute to ozone depletion and global warming. Unlike the familiar halogenated refrigerants, $\mathrm{CO}_{2}$ has a relatively higher saturation pressure at room temperature and a fairly high a critical pressure of 73.8 bar. Therefore, if $\mathrm{CO}_{2}$ were to be used in the standard vapour compression cycle the operation has to be in transcritical or in supercritical regions. Such operations bring in fluid behaviours and cycle control issues somewhat different to the experiences with subcritically operated familiar halogenated refrigerant. Being a natural fluid, $\mathrm{CO}_{2}$ is presently gaining an increased research attention for refrigeration and heat pumps applications. This paper attempts to present a general overview of $\mathrm{CO}_{2}$ as a refrigerant, potential applications, heat transfer behaviour etc., highlighting how it differs from common halogenated refrigerants.
\end{abstract}

Keywords: Carbon dioxide, refrigeration, heat pump, COP, transcritical

\section{Background}

Having understood the nature and the gravity of environmental damages halogenated refrigerants could cause, it is logical to consider natural alternatives, so that the mistakes similar to that of introducing chlotofluorocarbons (CFCs) in 1930s and 1940s would not be repeated. Since even the most comprehensive testing and evaluation program of refrigerants cannot exclude all possible unknown effects that may come in few years time after another set of chemical has been introduced as alternatives, turning into natural substances make more sense. Further, with widely accepted notion that natural refrigerant can do no or little overall harm, substances already in circulation in the biosphere such as air, $\mathrm{CO}_{2}, \mathrm{NH} 3$, water, hydrocarbons are receiving increased attention of refrigeration research.

Before the introduction of chlorinated refrigerants, say in the first three to four decades of 1900s, ammonia $\left(\mathrm{NH}_{3}\right)$, sulphur dioxide $\left(\mathrm{SO}_{2}\right)$, and carbon dioxide $\left(\mathrm{CO}_{2}\right)$ were practically successful refrigerants [1]. In 1930s and $1940 \mathrm{~s}$ chlorofluorocarbons (CFC) were highly promoted on account of their safety and harmlessness to the environment. With such benign introduction, almost all the fields in refrigeration gradually switched to $\mathrm{CFCs}$, expect for some instances of ammonia uses. However, by mid 1970s it was understood that the claims of environmental benignness and safety were both wrong, and significant damage to the environment has already being done due to use of CFCs in a period over 40 years.

Almost all the working fluids currently used in refrigeration have critical pressures in the range of 30 to 50 bar [1]. However, the exceptions are carbon dioxide, ammonia and water vapour with critical pressures of 73.8, 113, 221 bar respectively, which are well above the pressure ratings of standard compressors presently in the market. In the field of refrigeration, the mostly used temperature range with the largest number of applications and units in service would be about -40 to $+10^{\circ} \mathrm{C}$. When considering present stringent refrigerantselection criterion, efficiency etc., the choices of natural refrigerants for cooling applications in the above temperature range is limited to very few fluids, namely ammonia (R717), carbon dioxide (R744) and hydrocarbon (propane - $\mathrm{C} 3 \mathrm{H} 8$ or $\mathrm{R} 290$ and butane $-\mathrm{C}_{4} \mathrm{H}_{10}$ or R600).

The earth's atmosphere contains nearly $3 \times 10^{12}$ tons ( 3000 billion tons) of $\mathrm{CO}_{2}$, on the top of that about 25,000 million tons are added each year by anthropological activities [2] and $\mathrm{CO}_{2}$ is in constant circulation in the biosphere. Such

Eng.(Prof.) Leelananda Rajapaksha, MIE(Sri Lanka), MIIAR, CEng., MIMechE, BScEng. (First Class Hons), MEng, PhD, Associate Professor, Department of Mechanical Engineering, Faculty of Engincering, University of Peradeniya. 
large quantities being around us would be the best example that illustrates the harmlessness of $\mathrm{CO}_{2}$ as a refrigerant. On the other hand, $\mathrm{CO}_{2}$ is a greenhouse gas, however, with very little impact compared to halogenated refrigerants.

Therefore the use of $\mathrm{CO}_{2}$ from presently existing unlimited sources (mostly man made) will only postpone the release of a certain quantity to the environment. This, in a way, can be considered analogous to planting a tree to bind carbon for a certain period of time.

Up to about 1950s carbon dioxide was still a dominating refrigerant in marine applications, particularly for on board refrigeration [1]. After $\mathrm{CFCc}$ claimed the place of $\mathrm{CO}_{2}$ completely in 1930 s and 1940s, research on $\mathrm{CO}_{2}$ associated refrigeration did not receive much of an attention till about latter half of $1980 \mathrm{~s}$. By which time $\mathrm{CO}_{2}$ associated refrigeration issues started to pick up momentum, but this time as a potential natural refrigerant, with focus on applications such as use of $\mathrm{CO}_{2}$ in smaller refrigeration systems including automobile air conditioning [3,4] and heat pumps for water heating and drying [5]. Further, research attempts to overcome the undesirable issues arising from the use of $\mathrm{CO}_{2}$ as a refrigerant are many [6, 7]; use of $\mathrm{CO}_{2}$ in combination with other natural refrigerants such as ammonia or hydrocarbons to achieve lower working pressures is just one example in this context [6]. In addition, there are renewed interest for comprehensive understanding of heat transfer behaviour of $\mathrm{CO}_{2}$.

The revival of $\mathrm{CO}_{2}$ as a natural refrigerant is in the spotlight of present refrigeration research in a global scale. This paper attempts to present a general overview of $\mathrm{CO}_{2}$ as a refrigerant in the applications of vapour compression refrigeration and heat pump systems.

\section{2. $\mathrm{CO}_{2}$ and vapour compression refrigeration cycle}

\subsection{Carbon dioxide as a refrigerant}

Carbon dioxide is a non-flammable, non-toxic and relatively inert natural substance. Further, it is inexpensive, non-explosive, and abundant in the nature. However, as a refrigerant, the pressures and volume requirement of $\mathrm{CO}_{2}$ are vary greatly different to familiar ranges with common halogenated refrigerant. To elaborate on these aspects figure 1 and 2 present saturation pressure and saturation volume of $\mathrm{CO}_{2}$ together with those of three other selected halogenated refrigerants; R 12, R22, R134a.

As shown in Figure 2, at any given temperature the saturation vapour volume of $\mathrm{CO}_{2}$ is considerably lower, and the saturation pressures are considerably higher than those of the halogenated refrigerants considered. R12 is used in the above figures for comparison purposes. Considerably lower vapour volume results in smaller components sizes relative to a system using a halogenated refrigerant delivering the same capacity.

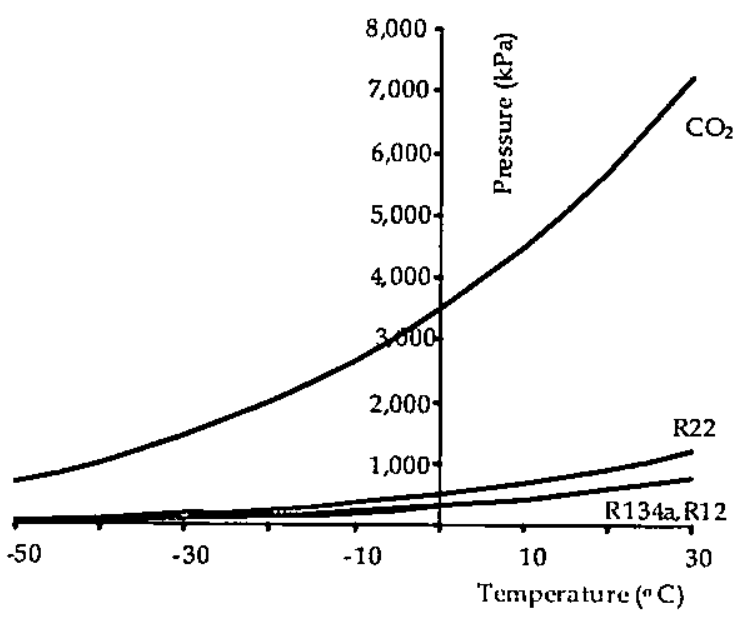

Figure 1 - Saturation pressure of R744 and selected halogenated refrigerants

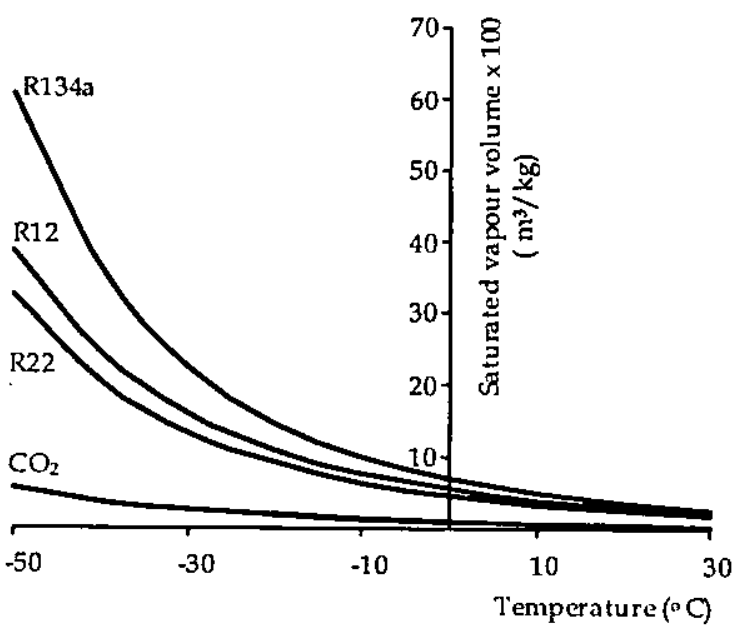

Figure 2 - Vapour volumes of R744 and selected halogenated refrigerants

Some important properties of $\mathrm{CO}_{2}$ are given in table 1, with few other selected refrigerants for the purpose of comparison of merits and 
demerits. Two important observations from table 1 are that $\mathrm{CO}_{2}$ has the lowest molar mass and the highest volumetric refrigeration capacity among the considered fluids. Implications of these attributes are discussed in section 2.3.

Table 1 - Selected characteristics and properties of refrigerants $[1,9,10]$

\begin{tabular}{|c|c|c|c|c|}
\hline & $\mathrm{R} 12$ & $\mathrm{R} 22$ & R134a & R744 \\
\hline Natural substance & No & No & No & Yes \\
\hline GWP (100 years) & 7100 & 1500 & 1200 & $1 /\left(\left(^{a}\right)\right.$ \\
\hline ODP & 1 & $0.05^{\mathrm{b}}$ & $\overline{0}$ & 0 \\
\hline Toxic & Yes & Yes & Yes & No \\
\hline Flammable & No & No & No & No \\
\hline Molar mass & 120.9 & 86.5 & 102.0 & 44.0 \\
\hline$P_{\mathrm{at}}(\mathrm{MPa})$ & 4.11 & 4.97 & 4.07 & 7.38 \\
\hline$T_{a t}\left({ }^{\circ} \mathrm{C}\right)$ & 112.0 & 96.0 & 101.1 & 30.9 \\
\hline$T_{n b}\left({ }^{\circ} \mathrm{C}\right)$ & -29.8 & -40.8 & -26.2 & -78.4 \\
\hline $\mathrm{Qv}\left(\mathrm{kJ} / \mathrm{m}^{3} @ 0^{\circ} \mathrm{C}\right)$ & 2740 & 4344 & 2860 & 22600 \\
\hline $\begin{array}{l}\text { First use in } \\
\text { refrigeration [rf } 3 \text { ] }\end{array}$ & 1931 & 1936 & 1990 & 1869 \\
\hline
\end{tabular}

(a) $\mathrm{CO}_{2}$ can be recovered from waste gases, therefore the effective GWP of commercial use, such as in refrigeration, can be considered zero

(b) Higher values can be found in different literature GWP - global warming potential, ODP - ozone depletion potential, Qv volumetric refrigeration capacity, $P_{\mathrm{c} t}, \mathrm{~T}_{\mathrm{ctr}}-$ critical pressure and temperature, $T_{\text {nh }}$ - normal boiling point temperature.

\subsection{Transcitical operation refrigeration cycle}

Figure 3 shows a pressure-enthalpy diagram for $\mathrm{CO}_{2}$, on which isotherms are marked at $20^{\circ} \mathrm{C}$ intervals. With a pseudo critical point temperature of $30.98^{\circ} \mathrm{C}$, it is obvious that if $\mathrm{CO}_{2}$ were to be used in a vapour compression application in the common range of cooling temperatures, say between -10 and $+10^{\circ} \mathrm{C}$, the heat rejection temperature will have to be above the critical point. This gives the refrigeration cycle a transcritical characteristic where, in a standard vapour compression system using $\mathrm{CO}_{2}$ as the refrigerant, the evaporation process will be subcritical $\left(\mathrm{T}_{\mathrm{ev}}<\mathrm{T}_{\mathrm{cr}}\right)$ at a constant temperature, while the heat rejection takes place supercritically ( $T_{c n}>T_{c r}$ ) not necessarily at constant temperature or pressure (the word condensation may not apply here as there is no phase change heat transfer involved). Since heat is rejected when the working fluid is in supercritical state, the pressure is independent of the temperature.

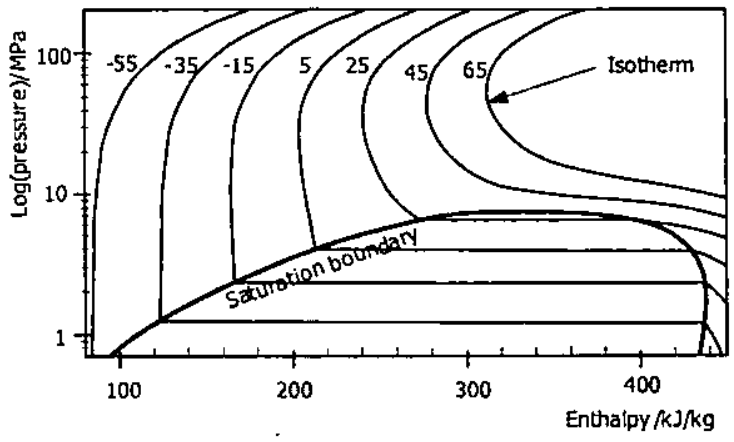

Figure 3 - Pressure-enthalpy diagram for $\mathrm{CO}_{2}$ (Generated using REFPROP | 11])

As can be seen from Figure 4a there can be more than one pressure for a given outlet temperature of the gas cooler (say for the temperature of point $A$ or $B$, the pressure can be that of $\mathrm{Pa}$ and $\mathrm{Pb}$ ). Further, the changes in discharge pressure change the specific refrigeration effect as well. This can be viewed as a means of controlling the capacity of the system, a feature not available for subcritically operated cycles. Further, changes in discharge pressure also vary the compressor power consumption, resulting changes in COP as well.

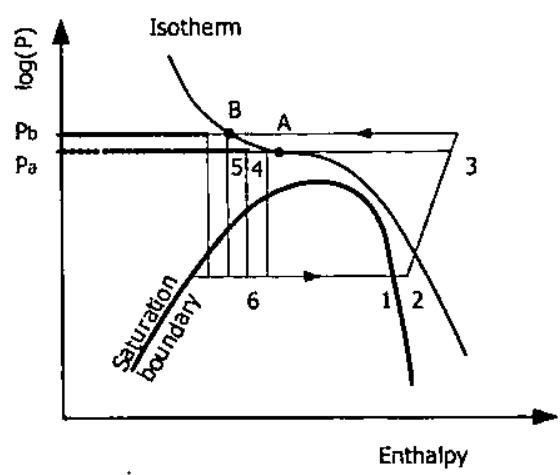

a) On pressure-enthalpy plane

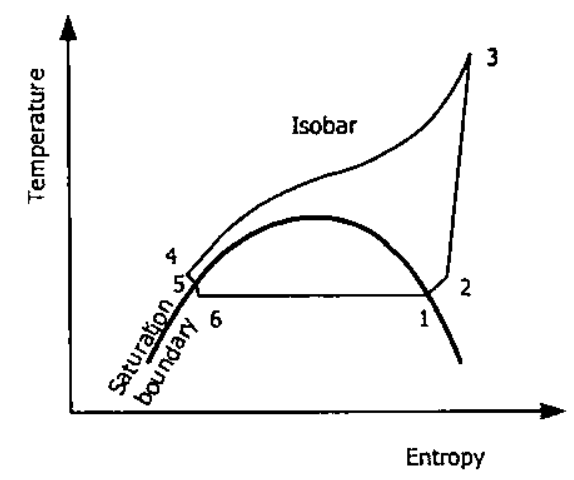

b) On temperature-entropy plane 


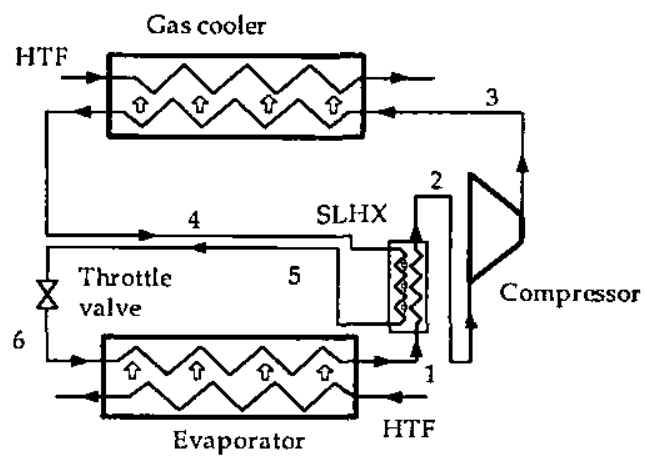

SLHX - suction line heat exchanger HTF - Heat transfer fluid

c) System schematic

Figure 4 - Vapour compression refrigeration cycle in transcritical operation

Further, in contrast to familiar subcritical isothermal condensation process with halogenated refrigerants, the heat rejection process takes place within a range of temperature, or with a certain temperatureglide, where the working fluid now undergoes a continuous increase in density (Figure $4 b$ ). The heat exchanger is therefore known as a gas cooler to represent the nature of heat transfer process inside.

Figure 5 shows the typical variation of specific refrigerating capacity (Qe), compressor power consumption (Wc) and coefficient of performance (COP) with discharge pressure [12]. The compressor power increases almost linearly with increasing discharge pressure. The specific refrigerating capacity, however, shows somewhat different behaviour where it initially changes at a higher rate with pressure (than that of the compressor power) and peak $\dot{s}$ at a certain pressure, after which changes almost linearly but at a lower gradient. Since COP presents a cumulative effect of both refrigeration capacity and power consumption, the COP also peaks around the same pressure where the capacity peaks and then starts to decline with increasing pressure. When a transcritical $\mathrm{CO}_{2}$ cycle operates with discharge pressure around where the capacity peaks the COP is at its best. This pressure is identified as the optimum pressure for normal operation. However, a momentary demand for more capacity could be met by operating the system at a higher discharge pressure at the expense of COP.

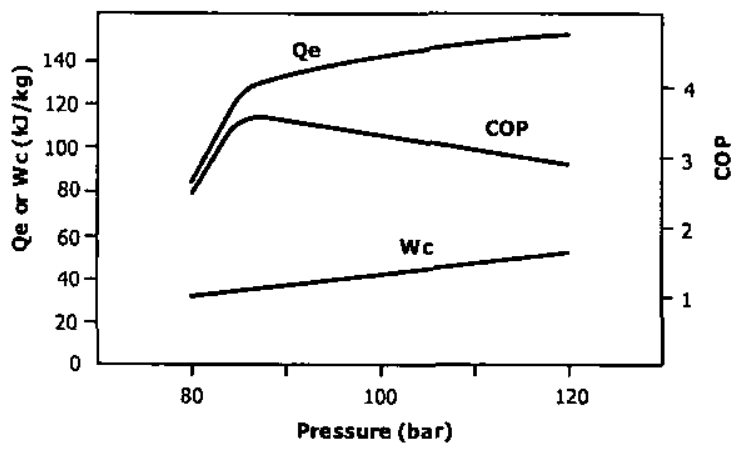

Figure 5 - Cooling capacity, compressor power and $\mathrm{COP}$ of transcritical $\mathrm{CO}_{2}$ system

The optimal heat rejection pressure $\left(\mathrm{P}_{\text {opt }}\right)$ mainly depends on the outlet temperature of the gas cooler, the evaporation temperature, and the performance of the compressor. A correlation for the optimal heat rejection pressure in terms of appropriate parameters that corresponds to the maximum COP is given in equation 1 [13]. This has been built up based on the evaporation temperature $\left(\mathrm{T}_{e}\right)$ and the outlet temperature of the gas cooler $\left(\mathrm{T}_{\mathrm{c}}\right)$ where the temperatures are in ${ }^{\circ} \mathrm{C}$ while the pressure is in bar.

$P_{\text {opt }}=\left(2.778-0.0158 T_{e}\right) T_{c}+\left(0.0381 T_{e}-9.34\right)$

When gas cooler pressure varies, both the COP and the refrigeration effect of the system will change. To make sure that the system operates at the optimal heat rejection pressure and meet the load requirement, a control method that simultaneously adjust both the speed of the compressor and the opening of the throttling valve is however yet to be developed.

\subsection{Applications and system configurations}

For various refrigeration and air conditioning applications (such as mobile and residential air-conditioners and heat pump water heaters) carbon dioxide has been reinvestigated as a working fluid [14]. With the renewed interest on $\mathrm{CO}_{2}$ and vapour compression technology, the performance of the transcritical $\mathrm{CO}_{2}$ cycle has been significantly improved by adapting various advanced components and cycle options such as a minichannel heat exchanger, an expander, an ejector, an internal heat exchanger, and multistage cycles. 
Among these, the $\mathrm{CO}_{2}$ system operating at relatively high pressures than the conventional refrigerant systems can favourably utilizes the minichannel heat exchangers as its gas cooler and evaporator due to its high density. Moreover, the $\mathrm{CO}_{2}$ cycle has smaller vapour and liquid density ratios than those of the conventional refrigerants, so that it experiences less maldistribution between the liquid and vapour phases in the minichannel heat exchanger.

Supercritical heat rejection in gas cooler takes place through sensible heat exchange, which suits heating applications in few ways. As the temperature of $\mathrm{CO}_{2}$ gradually decreases (not constant) high flow temperatures of the HTF, up to $90^{\circ} \mathrm{C}$, can be achieved without compromising the COP [12], where as a subcritically operated halogenated system would deliver the same duty at very low COP due to operation close to critical point temperature. Another issue that has a lesser influence on $\mathrm{COP}$ of $\mathrm{CO}_{2}$ cycle is the occurrence of pinch points inside the heat exchanger, which is a serious concern with subcritically operated systems.

Bypassing the flash gas generated during the expansion process of $\mathrm{CO}_{2}$, without allowing the gas to enter the evaporator, could improve the performance of direct expansion transcritical $\mathrm{CO}_{2}$ systems significantly [14]. Supplying $100 \%$ liquid $\mathrm{CO}_{2}$ to the evaporator will result in improved refrigerant distribution, reduced pressure drops and increased heat transfer performances. Further, the concept of flash gas bypass appears to be beneficial in improving the system design, particularly of combined systems used for simultaneous air conditioning and heat pumping applications. The improvement of the COP and cooling capacity are in the order of $7 \%$ $\sim 9 \%$ over a system without flash gas bypass [14], figure 6 shows typical hardware schematic of this system.

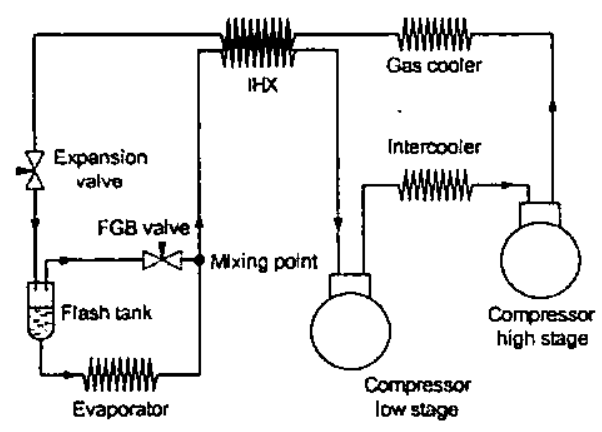

Figure 6 - Flash Gas Bypass concept with a two-stage compressor with intercooling
Using $\mathrm{CO}_{2}$ trans-critical systems in supermarket refrigeration is gaining interest with several installations already running in different European countries. There can be two types of system configurations potentially applicable for supermarket applications; centralized with accumulation tank at the medium temperature level and parallel with two separate circuits for low and medium temperature levels [15]. For ambient temperatures in the range 10 to $40^{\circ} \mathrm{C}$, the centralised system has a better COP. In the two configurations mentioned the evaporators are flooded type with single stage compression in low stage and two-stage compression with intercooling in the high stage.

Carbon dioxide has been experimented as a candidate for automobile refrigeration over last ten years and has gained considerable success as a potential refrigeration system for automobile air conditioning $[1,10]$. In this context, relatively high working pressure of $\mathrm{CO}_{2}$ has been considered as an advantage. This is based on to the fact that the required compressor volume for a given capacity is nearly inversely proportional to the suction pressure. Which means, combined with higher volumetric capacity of $\mathrm{CO}_{2}$ (Table 1 , which is between five and eight times higher at $0^{\circ} \mathrm{C}$ than those of the other refrigerants) compressor volume is reduced dramatically, resulting considerable reduction in the physical size of compressor itself when compared with conventional systems[10].

The relatively low molar mass of $\mathrm{CO}_{2}$ (Table 1) corresponds to a high evaporation enthalpy and further reduces the mass flow and required flow area of compressor valves and the piping system in general. Although a design pressure of the order of 100 to 120 bar is much higher than those used in halogenated refrigeration systems, it is by no means extreme compared with other technical equipment, and will not cause any particular design problems. The higher energy density of high pressure refrigerants willcertainly provide considerable practical and economical advantages, through reduced dimensions and weight, resulting in smaller, economical and compact systems $[1,10]$. Further, automobile air conditioning is the highest refrigerant emitters to the atmosphere among all refrigerant emissions, amounting to an estinated amount of 120,000 150,000 ton a year [10]. For mobile applications $\mathrm{CO}_{2}$ is very welcome as it is a natural substance, no harm from such large emissions, there is no refrigerant recycling or recovery issues attached no refrigerant monopoly governing the cost etc. 
Figure 7 shows a schematic of a $\mathrm{CO}_{2}$ refrigeration system adapted for automobile air conditioning. In this cycle the a small vessel, a receiver, at the exit of the evaporator is placed. The receiver serves to supply or absorb liquid for high side pressure regulation and ensures that sufficient refrigerant is available at all times, regardless of operating conditions. The operation of expansion valve is somewhat different to the conventional system in that it regulates to some extent the discharge pressure and control the cooling capacity. The dotted line link between the accumulator and evaporator (a bleed line) serves the purposes of providing an overfeeding to the evaporator as well as returning lubricant to the compressor.

Further, the system in Fig 7 is being used presently as a device for heating tap water for domestic and smaller commercial applications such as guest houses [12]. Water temperatures up to $90{ }^{\circ} \mathrm{C}$ can be achieved at competitive COPs, i.e. better than a halogenated refrigerant based system delivering the same load, when operated at the optimum discharge pressure. The system has a very good combined efficiency when used as a heat pump and air conditioner simultaneously by appropriately installing the system to absorb heat from space to be air conditioned [12]. In another potential application, the same cycle is used for drying laundry in commercial scale where the system delivers much better performances and COP in comparison with subcritically operated conventional vapour compression heat pump systems [16].

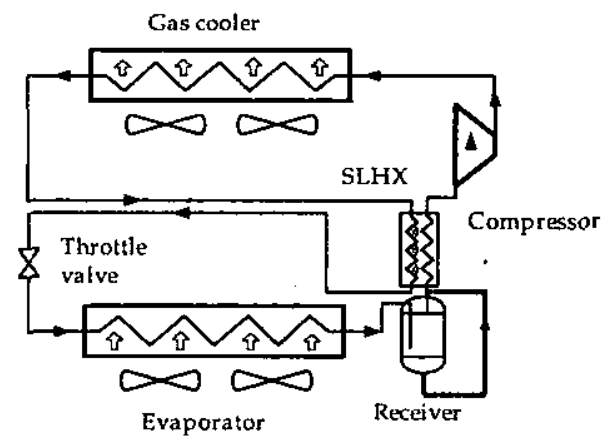

Figure 7 Schematic of $\mathrm{CO}_{2}$ automobile air conditioner system

\subsection{Combining with other fluids}

Relatively higher operating pressure and the inherently higher irreversibilities of $\mathrm{CO}_{2}$ (due to transcritical operation) in the refrigeration cycle can be partly solved by combining $\mathrm{CO}_{2}$ with another low pressure natural refrigerant. However, the suitable candidate for such mixing is more likely to be a hydrocarbon in order to maintain the naturalness of the refrigerant. Mixtures of $\mathrm{CO}_{2}$ and hydrocarbons (HCs) may be promising refrigerants since undesirable features of each refrigerant is counter balanced by the other to some extent by mixing. For example HC can help reduce the problems connected to high operating pressure of $\mathrm{CO}_{2}$ and $\mathrm{CO}_{2}$ in return can reduce the potential flammability risk. [17]. This approach makes $\mathrm{CO}_{2}$ more applicable for air conditioning systems as well, where transcritical operation could be changed to subcritical region. After the reinvention of $\mathrm{CO}_{2}$ as a refrigerant, the mixtures of $\mathrm{CO}_{2}$ with hydrocarbons gained interest due to superior heat transfer properties and system compactness with reduced cycle pressure and significantly reduced flammability compared to individual hydrocarbons [18].

In an attempt to match temperature glide of heat transfer fluid and $\mathrm{CO}_{2}$-propane mixture in an air conditioning application it has been reported that the mixing of the two refrigerant resulted in an increase system efficiency accompanied by a reduction of the cooling capacity. Further this system required relatively larger areas in order to capture the benefit of temperature glide matching [19].

In another variation, $\mathrm{CO}_{2}$ is used in cascade systems with hydrocarbons, separately in the high and low temperature circuit in the attempt to keep it all natural. For example, $\mathrm{CO}_{2}$ in high temperature circuit and propane in low temperature circuit forms a good combination of natural refrigerants for two-stage cascade system, where the amount of refrigerant (i.e the charge) is kept at very low levels by integrating advance heat exchangers [20]. On the other hand, in optimizing a $\mathrm{CO}_{2}$-propane cascade system for heating the overall performance of the system remains invariant with the effectiveness of the propane cycle (low temperature circuit) and increases when effectiveness of the $\mathrm{CO}_{2}$ cycle (high temperature circuit) is increased [21].

Use of natural fluid combination $\mathrm{CO}_{2}$ and $\mathrm{N}_{2} \mathrm{O}$ reveals that due to similar thermodynamic properties of the two refrigerants, $\mathrm{N}_{2} \mathrm{O}$ as low temperature fluid and $\mathrm{CO}_{2}$ as high temperature fluid in a cascade arrangement exhibit similar behavioural trends in a system where the refrigerants in the two circuits are swapped [22]. 


\section{Heat transfer and pressure drop}

\subsection{Flow boiling of subcritical $\mathrm{CO}_{2}$}

In general, the flow boiling heat transfer coefficient of pure $\mathrm{CO}_{2}$ is higher than the traditional refrigerants when compared at similar saturation temperatures [23]. Higher operating pressures of $\mathrm{CO}_{2}$ cycle results in high vapour densities, very low surface tensions, high vapour viscosities and low liquid viscosities. These result in flow boiling heat transfer and two-phase flow characteristics that are quite different from those of conventional halogenated refrigerants. High pressures and low surface tensions have major effects on nucleate boiling and clear dominance of nucleate boiling heat transfer has been observed even at very high mass velocities [24]. Therefore, $\mathrm{CO}_{2}$ has higher heat transfer coefficients than those of conventional refrigerants at the same saturation temperature.

However, the existing heat transfer correlations generally underpredict the experimental data of $\mathrm{CO}_{2}$. Further, dry-out may occur at moderate vapour quality in $\mathrm{CO}_{2}$ flow boiling, particularly at high mass velocity and high temperature conditions. At lower pressures significant deviations for the flow patterns of $\mathrm{CO}_{2}$ compared those developed for other fluids have been observed [24].

It has been experimentally established that the boiling $\mathrm{HTC}$ of $\mathrm{CO}_{2}$ is highly dependent on the vapour quality, heat flux and saturation temperature. Further, the boiling heat transfer coefficient of $\mathrm{CO}_{2}$ in horizontal smooth tubes is about $87 \%$ and $93 \%$ higher than those of R-22 and $\mathrm{R}-134 \mathrm{a}$ respectively [25]. Another observation is that the HTC of R134a and R22 increase with quality, whereas those of $\mathrm{CO}_{2}$ decrease with vapour quality [25].

The pressure drop is much lower than that of R22 about $10 \%-15 \%$ of that of R22. The lower pressure drop is attributed to its unique thermal properties mentioned previously [24,25]. Further, the boiling pressure drop of $\mathrm{CO}_{2}$ increases with increasing mass flux, and decreases with increasing saturation temperature.

\subsection{Convective cooling of supercritical $\mathrm{CO}_{2}$}

During supercritical heat rejection, $\mathrm{CO}_{2}$ stays in the gas state through out the heat rejection process (no phase changing) so that the heat exchanger is appropriately termed a gas cooler. Therefore, when using $\mathrm{CO}_{2}$ the heat transfer coefficient and pressure drop characteristics of high side heat exchanger is considerably different from those of familiar subcritical of halogenated refrigerants.

When supercritical $\mathrm{CO}_{2}$ is cooled in smooth horizontal tubes the HTC increases as the cooling process progresses, and reaches a maximum and then decreases. The increase in HTC correlates with the increase in specific heat of $\mathrm{CO}_{2}$ around pseudocritical temperature [26]. However, the maximum value attained by the HTC is affected negatively by the pressure drop. Both the HTC and pressure drop increases with increasing mass flux. However, the pressure drop appears to be independent of inlet pressure at lower temperatures than the pseudocritical temperature, where as, the pressure drop decreases significantly with increasing pressure at temperature higher than the pseudocritical temperature [26]. Test results showed that the average gas cooling heat transfer coefficient decrease by $20.4 \%$ and the average pressure drop was increased by 4.8 times when the oil concentration was increased from 0 to 4 wt.\% [27].

\subsection{Heat transfer and pressure drop in the presence of lubrication oils}

In actual situation a mixture of lubricant and the refrigerant is subjected to flow boiling in the evaporator, or convective cooling in the gas cooler, not just pure refrigerant. In the mixture of lubricant-refrigerant, the oil tend to have relatively a higher viscosity with preferential evaporation of refrigerant from the mixture [23].

The lubricating oil in the heat exchangers deteriorates the heat transfer performance and increases the pressure drop. The experience with CFCs and HCFCs is that the flow boiling heat transfer coefficient tend to drop rapidly when oil concentration exceeds $5 \%$. Impact of the presence of lubricant is especially greater in the minichannel heat exchangers than in the conventional fin-and-tube heat exchangers since the oil can block some minichannel ports [27]. 
Though presently there is little experimental data available to support a generalized view of the degradation of flow boiling heat transfer coefficient of $\mathrm{CO}_{2}$ in the presence of oil, the fact that the presence of oil degrade the flow boiling HTC of $\mathrm{CO}_{2}$ holds true. Further, the existing correlations that predict the HTC of refrigerant and oil mixtures appears to have large deviations (or error margins) such that the use of those established correlations for halogenated refrigerants carry a considerable uncertainty.

When considering the mixing nature of common lubricant, $\mathrm{CO}_{2}$ exhibit complete immiscibility with alkyl naphthalene (AN), alkyl benzene (AB) and polyalphaolefin (PAO), partial miscibility with polyalkylene glycol (PAG) and complete miscibility with polyol ester (POE) lubricant. As such, depending on the system design, the familiar lubricant such as POE and PAG could be used with $\mathrm{CO}_{2}$ as the refrigerant [23].

\section{Summary}

In this paper, changes in conventional subcritically operated vapour compression refrigeration cycle were highlighted with a view of bringing out pros and cons of using carbon dioxide as a natural refrigerant. As it can be observed from the presented information, with the advancements in appropriate fabrication technologies and material, the issue of having to operate at relatively high pressure levels when using $\mathrm{CO}_{2}$ will no longer be a concern of the system designer as those concerns outweigh the cost and environmental benefits brought in by $\mathrm{CO}_{2}$. In other words, good heat transfer performances of $\mathrm{CO}_{2}$ will certainly lead to compact and smaller systems, addressing the cost of material and cost of refrigerant very attractively, with the monopoly associated with refrigerants and issues of recycling refrigerants making non existence.

It was evident from the presented information that $\mathrm{CO}_{2}$ is a versatile refrigerant, which with appropriate system hardware and system layout changes, can be applied to many diverse applications ranging from simple cooling to heating, drying and combined heating and air conditioning. Among which the applications of air conditioning and drying are of interest across many local industries. Therefore, carbon dioxide is perceived as a natural refrigerant with a long term future in refrigeration and refrigeration associated industries.

\section{References}

1. Gustav Lorentzen, Revival of carbon dioxide as a refrigerant, Int. Journal of Refrigeration, 1994, Vol 17, $292-301$.

2. http://micpohling.wordpress.com/, visited on $23 / 02 / 2009$

3. J. Steven Brown, Samuel F. Yana-Motta, Piotr A. Domanski, Comparitive analysis of an automotive air conditioning systems operating with $\mathrm{CO}_{2}$ and $\mathrm{R} 134 \mathrm{a}$, Int. Joumal of Refrigeration, 2002 , Vol 25, $19-32$.

4. IlR News, 2002, Int. Journal of Refrigeration, Vol 25, 1011 - 1013.

5. 8. Petter Neksa, Havard Rekstad, G R Zakeri, Per A Schiefloe, $\mathrm{CO}_{2}$ heat pump water heater: characteristics, system designand experimental results, Int. Joumal of Refrigeration, 1998, Vol 21, $172-179$.

6. Vanna Cassona, Luca Cecchinatoa, Marco Corradia, Ezio Fornasieria, Sergio Girottob, Silvia Minettob, Lorenzo Zambonia, Claudio Zilioa, Optimisation of the throttling system in a $\mathrm{CO}_{2}$ refrigerating machine, Int. Joumal of Refrigeration, 2003, Vol 26, $926-935$.

7. Stefan Elbel, Pega Hrnjak, Flash gas bypass for improving the performance of transcritical R744 systems that use microchannel evaporators, Int. Journal of Refrigeration , 2004, Vol 27, 724 735.

8. Neeraj Agrawala and Souvik Bhattacharyya, Parametric study of a capillary tube-suction line heat exchanger in a transcritical $\mathrm{CO}_{2}$ heat pump cycle, 2008, Energy Conversion and Management, Vol 49, Issue 11, Pages 2979-2985.

9. Man-Hoe Kima, Jostein Pettersenb, Clark W. Bullard, Fundamental process and system design issues in $\mathrm{CO}_{2}$ vapor compression systems, Progress in energy and combustion science, 2004 (30), 119 - 174.

10. Gustav Lorentzen and Jostein Pettersen, A new, efficient and environmentally benign system for car air-conditioning, int. Journal of Refrigeration, 1993 Vol 16 No 1, pp 4-12

11. REFPROP, NIST standard reference database 23, 2001.

12. Willy Adriansyah, Combined air conditioning and tap water heating plant using $\mathrm{CO}_{2}$ as refrigerant, Energy and Building, 2004(36)690-695. 
13. S.M. Liaoa, T.S. Zhaoa, A. Jakobsen, A correlation of optimal heat rejection pressures in transcritical carbon dioxide cycles, Applied Thermal Engineering, 2000, (20) 831-841.

14. Stefan Elbel, Pega Hrnjak, Flash gas bypass for improving the performance of transcritical R744 systems that use microchannel evaporators, Int. Journal of Refrigeration, 2004 (27) 724-735

15. Samer Sawalha, Theoretical evaluation of trans-critical $\mathrm{CO}_{2}$ systems in supermarket refrigeration. Part I: Modeling, simulation and optimization of two system solutions int. Joumal of Refrigeration, 2008 (31) 516 - 524

16. K. KloÈ cker, E.L. Schmidt, F. Steimle, Carbon dioxide as a working fluid in drying heat pumps, Int. Joumal of Refrigeration 2001 (24) $100-107$

17. Ju Hyok Kim, Jin Min Cho, Il Hwan Lee, Jae Seung Lee, Min Soo Kim, Circulation concentration of $\mathrm{CO}_{2} /$ propane mixtures and the effect of their charge on the cooling performance in an air-conditioning system, Int. Journal of Refrigeration, 2007 (30) 43-49

18. J. Sarkar, S. Bhattacharyya, Assessment of blends of $\mathrm{CO}_{2}$ with butane and isobutane as working fluids for heat pump applications, International Journal of Thermal Sciences 2009, doi:10.1016/j.ijthermalsci.2008.12.002, article accepted and in press currently

19. Ju Hyok Kim, Jin Min Cho, Min Soo Kim, Cooling performance of several $\mathrm{CO}_{2} /$ propane mixtures and glide matching with secondary heat transfer fluid, Int. Joumal of Refrigeration, 2008 (31), $800-806$.

20. Souvik Bhattacharyya, S. Mukhopadhyay, J. Sarkar, $\mathrm{CO}_{2}-\mathrm{C}_{1} \mathrm{H} 8$ cascade refrigeration-heat pump system: Heat exchanger inventory optimization and its numerical verification, Int. Journal of Refrigeration, 2008 (31) 1207 $-1213$.
21. Souvik Bhattacharyya, S. Mukhopadhyay, A. Kumar, R.K. Khurana, J. Sarkar, Optimization of a CO $2-\mathrm{C} 3 \mathrm{H} 8$ cascade system for refrigeration and heating, Int. Joumal of Refrigeration, 2005 (28) 1284-1292

22. Souvik Bhattacharyya, Anirban Garaia, Jahar Sarkar, Thermodynamic analysis and optimization of a novel $\mathrm{N}_{2} \mathrm{O}-\mathrm{CO}_{2}$ cascade system for refrigeration and heating, Int. Journal of Refrigeration, 2008, doi:10.1016/j. ijrefrig.2008.09.008, accepted article in press

23. Xiumin Zhao, Pradeep Bansal, Critical review of flow boiling heat transfer of $\mathrm{CO}_{2}$-lubricant mixtures, Int J Heat and mass transfer, 2009 (52) 870-879.

24. Lixin Cheng, Gherhardt Ribatski, Leszek Wojtan, John R. Thome, New flow boiling heat transfer model and flow pattern map for carbon dioxide evaporating inside horizontal tubes, Int I Heat and mass transfer 2006 (49) 4082-4094.

25. Hoo-Kyu Oh, Hak-Geun Ku, Geon-Sang Roh, Chang-Hyo Son, Seung-Jun Park, Flow boiling heat transfer characteristics of carbon dioxide in a horizontal tube, Applied Thermal Engineering 2008 (28) 1022-1030

26. Seok Ho Yoona, Ju Hyok Kimb, Yun Wook Hwangb, Mm Soo Kimb,Kyoungdoug Minb, Yongchan Kimc, Heat transfer and pressure drop characteristics during the in-tube cooling process of carbon dioxide in the supercritical region, Int. Journal of Refrigeration, 2003 (26) 857-864.

27 Rin Yun, YunhoHwang, ReinhardRadermacher, Convective gas cooling heat transfer and pressure drop characteristics of supercritical $\mathrm{CO}_{2}$ /oil mixture in a minichannel tube, int I Heat and mass transfer, 2007 (50) 4796-4804. 